\title{
Tribotronic Analysis of Internal Combustion Engine Compression Ring
}

\author{
Konstantinos Tsatsoulis, Anastasios Zavos and Pantelis G. Nikolakopoulos* \\ Machine Design Laboratory, Department of Mechanical Engineering and Aeronautics, University of Patras, Greece \\ *Corresponding author: Pantelis G. Nikolakopoulos (pnikolakop@upatras.gr)
}

Manuscript received 27 January 2021; accepted 21 April 2021; published 15 June 2021

\begin{abstract}
The influence of operating conditions of the compression rings on the engine power losses affects confoundedly the design of the Internal Combustion Engines (ICEs). Normalized parameters such as Friction Mean Effective Pressure (FMEP) were used to regulate power losses. The purpose of this work was to create a primary control model of the friction mean effective pressure using an automatic control system. This study incorporates the creation of a mixed-hydrodynamic model for the top compression ring in MATLAB computing environment. The load of ring asperities was predicted using Greenwood-Tripp stochastic model. The pressure distribution along the ring face-width was determined using Reynolds equation through finite difference method with the half-Sommerfeld boundary condition for cavitation outlet zone. This was accomplished by finding the maximum ring pressure for a range of engine speeds and lubricant temperatures. Additionally, the computed results concerning the maximum pressure and the PID controlled characteristics are proposed and compared using a cavitation model. Regarding the automatic system, a PID controller was built using SIMULINK. The numerical results showed that FMEP could be the effective parameter in order to control the engine operation and to proof the tribotronics design in an Internal Combustion Engine.
\end{abstract}

\section{Keywords}

compression ring, mixed-hydrodynamic lubrication, Reynolds equation, friction mean effective pressure (FMEP), MATLAB, automatic control

\section{Introduction}

Internal Combustion engines have a dominant role in various economic activities, such as transportation and electricity generation $[1,2]$. A quick view is enough to understand that most of the internal sub-systems associated with fuel and oil consumption are important. One of those systems with a critical effect on the referred issues is the piston rings. Regarding its functional demands, the top compression ring is exposed to rapidly changing loads due to its high pressure, low speed and pure lubricant environment. The impact of piston ring-bore contact has also been investigated by many engine suppliers to optimize the main design issues. Thus, innovative piston rings with high-quality standards should be manufactured and produced [3,4]. The proposed strategies to find the best ring tribological performance include changing the engine parameters such as pressure, speed and lubricant temperature. The following paragraph provides the forthcoming progressions in this field with the major challenges.

The engine power losses account for $20 \%$ of all its total losses, and the contribution from the top compression ring is between $30 \%$ and $40 \%$, because of its primary function in sealing [5]. The environment in the ring-bore conjunction is one of the most complex to investigate due to the transient nature of this contact and the variation of lubrication regimes as presented by Dowson [6]. Particularly, this motion is responsible for frictional loss and blow-by. Therefore, a plethora of factors need to be carried out simultaneously including conjugating surfaces, gas blow-by, and ring dynamics. In 1960, Furuhama [7] presented experimental measurements for the ring-liner system. This study showed that the ring-liner contact was subjected to transient lubrication in terms of the load and temperature. Numerical predictions and experimental measurements of the piston ring-liner mechanism were also reported by Jeng [8], Priest et al. [9] and Ma et al. [10]. The film thickness and the produced frictional losses were evaluated using the basic lubrication theory of Reynolds. It was found that in-cylinder pressure, speed and viscosity have dominant role to engine power losses. Nikolakopoulos [11], Rahmani et al. [12], and Bewsher et al. [13] presented results by including the effects of the ring-liner conjugating surfaces, thermal conditions and in-cylinder de-activation. These studies were used CFD and numerical models for piston ring-liner conjunction. They found that the profiles of the ring-cylinder surfaces and the flow conditions may strongly influence the mechanisms of generated friction and fuel consumption. With regard to 
lubricant flow within the contact, there is detailed work from many tribologists. Arcoumanis et al. [14], Sawicki et al. [15] and Shahmohamadi et al. [16] have studied various cavitation models comparing different numerical approaches. These researchers found that the cavitation affects the load carrying capacity, as well as the generated friction and heat transfer. To conclude, another major parameter is also elastic-ring-model behaviour comprising in-plane and out-of-plane ring motions. Tian et al. [17] and Baker et al. [18] built ring tribodynamics models that provide more realistic numerical results with the published experimental predictions in the literature. Particularly, the results showed that the ring's sealing function is affected due to the flutter or twist into the piston groove.

In recent years, tribotronics is a novel concept for tribological design, where sensors and actuators are installed in machine elements or systems to dynamically influence on their performance. This can make a component an intelligent device that monitors and controls itself to enhance its own health state and suitable performance. Furthermore, they have the ability of feedback information regarding their performance and health state for the wear and lubrication for example. So, technologies like the Internet of Things, can be applied to perform control of the machine element and system, improving their maintenance strategies or the performance overall. Limited papers have been presented or published dealt with tribotronics in tribology. Sherrington et al. [19, 20], in their papers, investigated that, using well established theory, and control of lubricating film, these can be used to moderate operating parameters such as temperature, lubricant leakage and power loss. They also mentioned some limitations that the direct measurement of lubricating film thickness is not an easy task of such measurements and might be limited to applications in research and development. Bahrudin el al. [21] presented a part of tribotronic system on a pin-on-disc tribometer focusing on friction measurement using load cell. The analysis managed using MATLAB software to measure coefficient of friction, and two case studies made in order to prove the validity of the measurement. Glavatskih and Höglund [22] discussed the concept of tribotronics or active tribology and the implementation of smart machine concepts, in several applications. Moreover, they comment on the up to date, since then, various possibilities for tribotronics sytems mentioned in the literature. Zhang et al [23] shown the perspective for implementing novel micro/nano-electromechanical devices, by coupling the triboelectricity with semiconductor defined as tribotronics, that may derive plenty of potentially important research interests and applications in sensing. Such application could be the energy harvesting, human-machine interfacing, MEMS/NEMS and active flexible/stretchable electronics.

In this paper, the tribotronics design concept is applied in Internal Combustion Engine in order to control the performance of the engine though the FMEP, and more specific concerning the compression piston ring. The novelty of the paper is the development of a complete model in order to obtain the characteristics of a primary control model, for friction control of an internal combustion engine in terms of the friction mean effective pressure, including the lubricant temperature and cavitation effects. The field of the fluid film is computed through Reynolds equation using the finite difference technique. Furthermore, either using Navier Stokes equations or Reynolds equation for the solution, the suitable cavitation model, and under certain operational conditions could affect the results. Particularly, the relevant results regarding the FMEP and the
PID controlled characteristics are also presented and compared using a cavitation model. This trend can lead in a wishable engine performance.

\section{Basic theory}

\subsection{Ring -liner lubrication}

This model represents a two-dimensional ring-bore conjunction [24, 25]. Reynolds equation is used here in order to solve the fluid film field between piston ring and cylinder liner. The central difference discretization is used with the advantage of improved accuracy for the second order Poiseuille flow terms. The Reynolds equation is written as [26]:

$$
\frac{\partial}{\partial x}\left(h^{3} \frac{\partial p}{\partial x}\right)+\frac{\partial}{\partial y}\left(h^{3} \frac{\partial p}{\partial y}\right)=6 \mu U \frac{\partial h}{\partial x}+\frac{\partial h}{\partial t}
$$

This form of the equation includes the flow in the direction of entraining motion, $x$ as well as side-leakage from the contact, $y$. It also includes the effect of squeeze film action. Solution of the equation requires the film shape, $h$, under assumed isothermal conditions. Boundary conditions are necessary for the solution of Reynolds equation. In this first approach, the atmospheric pressure is assumed as boundary conditions ( $x=$ $-b / 2, x=b / 2$ ), (Fig. 1), as the ring operates between area with no pressure drop [27]. The inlet boundary under fully flooded conditions becomes:

$$
P_{x=\mp \frac{b}{2}}=P_{a}
$$

The easiest way to treat cavitation is to apply the half Sommerfeld solution, which means that the part with negative pressure is replaced with zeros. The drawback of using that method is that the load carried by the ring is underestimated and mass continuity of flow is not fulfilled. A better way to treat the cavitation is to apply the JFO (Jakobsson-Floberg-Olsson) boundary conditions developed in [28] and [29], which says that $\partial p / \partial x=0$ at the cavitation rupture boundary. This is an ongoing research, since this paper focused to proof the tribotronics design in the compression piston ring on an ICE.

In the application of ring, $P_{a}$ is the pressure at the ring inlet which depending on the direction of the motion of the ring, thus it can be the combustion chamber pressure or the crankcase (or inter-ring) pressures. In the Fig. $1, x=c$ is the possible position of lubricant film rupture.

The lubricant film distribution is correlated directly with the ring face profile. The corresponding barrel face ring shape is presented in Fig. 1. Thus, the lubricant film can be written as follows:

$$
h(x, y, t)=h_{\min }(t)+h_{s}(x, y)
$$

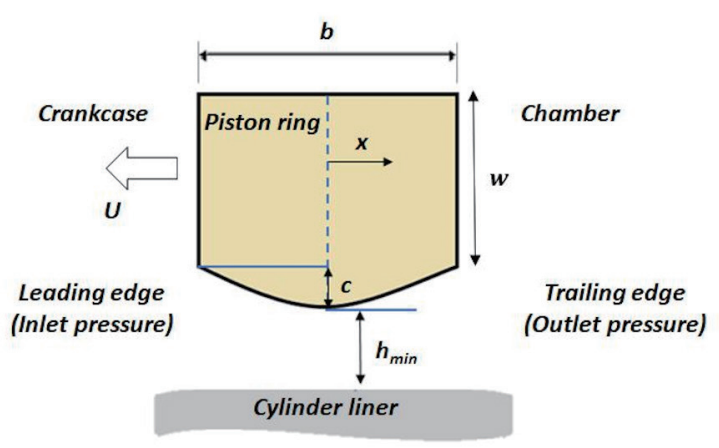

Fig. 1 Basic parameters in the ring-liner conjunction 
where $h_{\min }(t)$ is the minimum oil thickness of ring-cylinder conjunction, $h_{s}(x, y)=\frac{c y^{2}}{(b / 2)^{2}}$ is the ideal parabola shape. In this analysis, the local contact deformation and thermoelastic contribution are not obtained in Eq. (3). In practical, the relevant published papers $[30,31]$ showed that the local elastic asperity contact is very low for coated compression rings. The sliding speed of the ring can be expressed as [32]:

$$
V_{p}(\varphi)=r \Omega\left(\sin \varphi+\frac{\lambda_{C R}}{2} \sin 2 \varphi\right)
$$

where $r$ is the crank-pin radius, $\Omega$ is the rotational crankshaft speed, $\varphi$ is the crank angle and $\lambda_{C R}$ is the control ratio.

In this study, the lubricant dynamic viscosity was measured using an EH105 capilary tube viscometer. The viscometer and its main parts were presented by Nikolakopoulos et al. [33]. During the measurements, the pressure was up to 2 $\mathrm{MPa}$ and the temperature varied between $25^{\circ} \mathrm{C}$ and $80^{\circ} \mathrm{C}$. The chosen lubricant was the synthetic oil SAE 10W40, which is commonly used in the automotive industry $[33,34]$. Figure 2 shows the measured viscosity for SAE 10W40 under different test conditions. Fresh and aged oil conditions were taken into account.

\subsection{Mechanical friction losses}

Lost mechanical work is referred to as friction work and contains all engine losses. These losses are pumping losses, mechanical friction losses and auxiliary equipment losses. Friction losses result from the forces acting between surfaces with relative motion (Fig. 3). In the sliding and rotating parts of a machine the friction force and consequently the losses due to these forces occur due to shear stresses in the layers of the lubricant.

To determine the friction losses, the normalized parameters are defined, such as the mean effective pressure (MEP). The Mean Effective Pressure (MEP) is classified as:

- Brake mean effective pressure (BMEP)

- Indicated Mean Effective Pressure (IMEP)

- Friction mean effective pressure (FMEP)

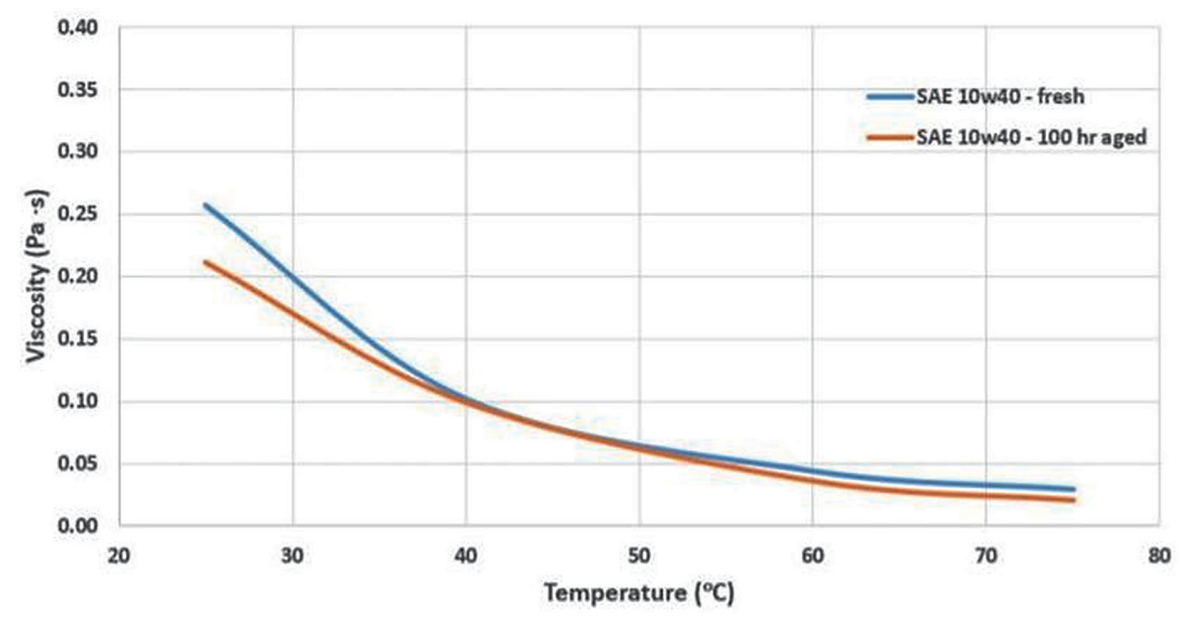

Fig. 2 Measured viscosity for SAE10W40 under different test conditions

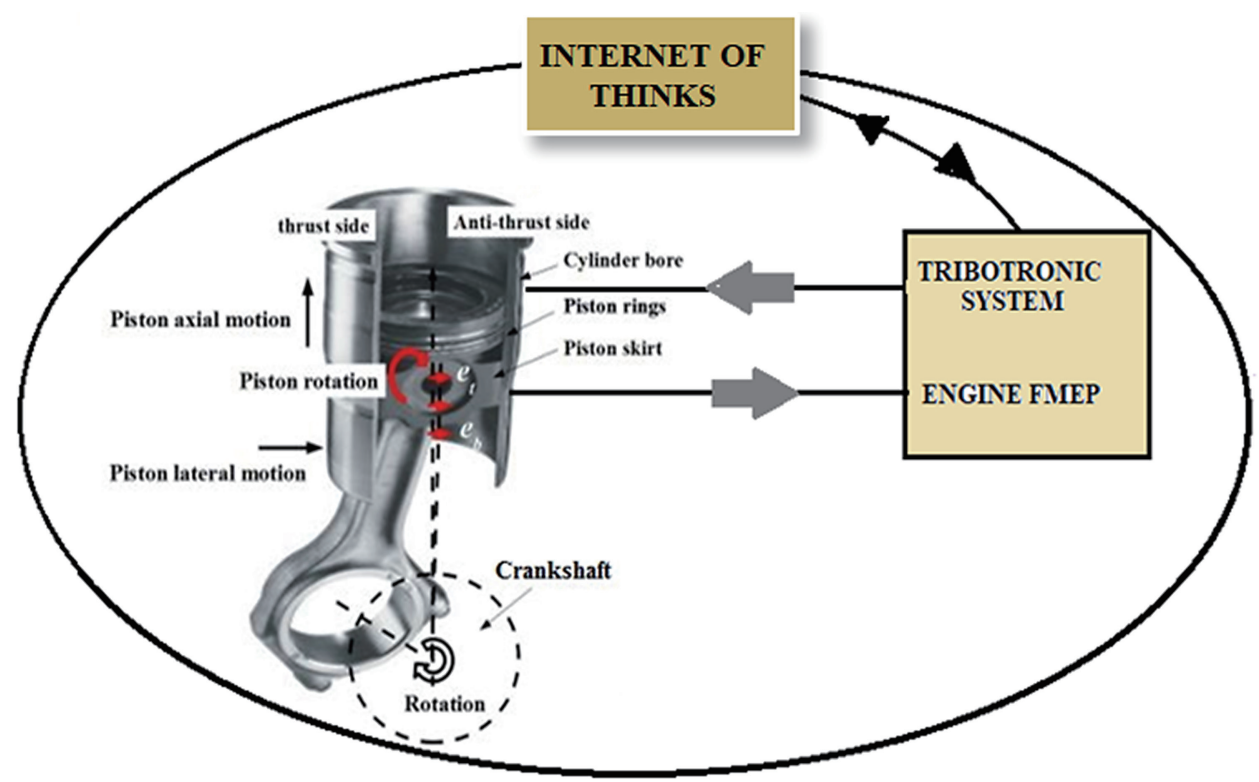

Fig. 3 A schematic view of the tribotronic system of an Internal Combustion Engine 
Friction mean effective pressure (FMEP) is an indicator of the mean effective pressure of the engine lost through friction and it's the difference between indicated mean effective pressure and brake mean effective pressure.

$$
\begin{aligned}
& \text { BMEP }=\text { IMEP }- \text { FMEP } \\
& n m=\frac{\text { BMEP }}{\text { IMEP }}=\frac{\text { IMEP }- \text { FMEP }}{\text { IMEP }}=1-\frac{F M E P}{I M E P}
\end{aligned}
$$

Friction mean effective pressure models are appeared in ref. [35] as follows:

- Chen \& Flynn: FMEP $=0.137+\frac{P \max }{200}+0.162 \cdot u$

- Branes \& Moss: FMEP $=0.97+0.15 \cdot \frac{n}{1000}+0.05 \cdot\left(\frac{n}{1000}\right)^{2}$

- Winterbone Model (1986):

$$
F M E P=0.061+0.15 \cdot \frac{P \max }{60}+0.294 \cdot \frac{n}{1000}
$$

where FMEP is the friction mean effective pressure, $P_{\max }$ is the maximum gas pressure and $n$ corresponds to the engine speed.

In this work, the Winterbone approach was modelled that contains the speed and maximum pressure.

\section{Method of the ring-liner model solution}

This analysis includes in-plane ring load balance in steady state manner. At each crank angle, the produced load in the ring-cylinder clearance is obtained to be equal with the total outward force behind the ring profile. Therefore, the in-plane ring motion is summarized in Eq. (10) as follows:

$$
\underbrace{F_{e l}}_{\text {elastic force }}+\underbrace{F_{b k}}_{\text {back gas force }}=\underbrace{W_{\text {hydd }}(\phi)}_{\text {hydrodynamic generated force }}+\underbrace{W_{\text {cont }}(\phi)}_{\text {asperities generated force }}
$$

In this study, the effects of asperities were performed by Greenwood-Tripp stochastic approach [36]. The asperity height distribution is assumed to be Gaussian, thus the produced contact pressure by normally distributed asperity heights can be expressed as:

$$
\left\{\begin{array}{l}
W_{\text {cont }}=\frac{16 \sqrt{2}}{15} \pi(\zeta \kappa \sigma)^{2} \sqrt{\frac{\sigma}{\kappa}} E^{\prime} A F_{5 / 2}(\lambda) \\
A_{\text {cont }}=\pi^{2}(\zeta \kappa \sigma)^{2} A F_{2}(\lambda)
\end{array}\right.
$$

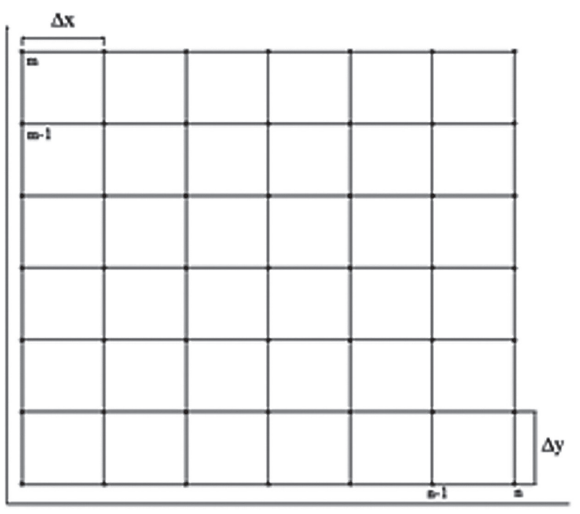

where the quantities $\zeta \kappa \sigma$ and $\frac{\sigma}{\kappa}$ are the dimensionless roughness parameter and the asperity slope, respectively.

Two outward forces are applied between the piston and the back profile of the ring. The total combustion pressure is used to determine the pressure acting behind of the ring, therefore the back-gas force is given as:

$$
F_{b k}=\pi D_{c y l} b p_{b k}(\varphi)
$$

Additionally, the ring tension force is:

$$
F_{e l}=\pi D_{c y l} b p_{e l}
$$

where the elastic pressure is $p_{e l}=\frac{d_{g a p} E_{r} I_{r}}{3 \pi b\left(\frac{D_{c y l}}{2}\right)^{4}}$ for the top ring cross section parameter $I_{r}=\frac{b d^{3}}{12}$.

For the hydrodynamic reaction, the load carrying capacity, Whyd, along the ring face is defined as:

$$
W_{\text {hyd }}=\pi D_{c y l} \int_{-b / 2}^{b / 2} p_{h y d} d x d y
$$

The method used to solve the Reynolds differential equation is that of finite differences. The pressure change occurs only on the x-axis component as in the present work we are dealing with a narrow compression ring. The sizes $\mathrm{n}$ and $\mathrm{m}$ are defined, which correspond to the number of maximum cells in the grid. In more details. the parameter $\mathrm{n}$ corresponds to the $\mathrm{x}$ - axis and the parameter $\mathrm{m}$ corresponds to the $\mathrm{y}$-axis.

The two numbers can be defined by the user of the algorithm, however in this work the fixed numbers for our calculations were evaluated. We defined $n=200$ cells and $m$ $=10$ cells (Fig. 4). Since, the pressure does not change on the $\mathrm{y}$ axis, we can define $\mathrm{m}$ much smaller than $\mathrm{n}$. In this way, the computer save time from unnecessary repetitions. Therefore, it is calculated once and copied to the other cells. By applying control of the percentage deviation of the sum of all values calculated for the lubricant pressure, the convergence of our results is controlled. In this work, the limit value is taken as $10^{-4}$ and the maximum number of repetitions to achieve this percentage is 2000 .

$$
\text { percentage }=\frac{\mid \text { sum }_{\text {new }}-\text { sum }_{\text {old }} \mid}{\mid \text { sum }_{\text {new }} \mid}
$$

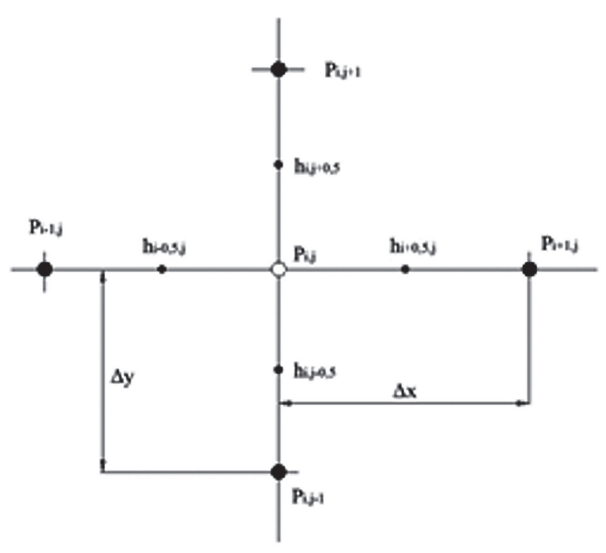

Fig. 4 Grid with $n, m$ cells and grid detail 
where sum $_{\text {new }}$ : the new sum of pressures when repeated and sum $_{\text {old }}$ the previous sum of pressures.

At any crank angle, the ring balance should be implemented. Particularly, the ring balance is a quasi-static analysis. For clarity, the main equations are presented and rewritten here.

The load balance is made when the Eq. (16) is confirmed as:

$$
X=\frac{|W(\varphi)-F(\varphi)|}{\max \{F, W\}} \leq 0.1 \%
$$

If the balance is not achieved, then the minimum film thickness is re-calculated through the iterative process of the Eq. (17). In this analysis, the value of the parameter $\chi$ is taken as: $\chi$ $=0.05$.

$$
h_{\min }^{n+1}=(1+\chi X) h_{\min ,}^{n} n \geq 1
$$

\section{Automatic control system -simulink model}

The design of the tribotronic automatic control system is chosen here regarding the equation that approaches the friction mean effective pressure FMEP. As mentioned in the introduction, the purpose is to adjust the appropriate parameters through an automatic control system to achieve the maintenance of FMEP at low levels. To solve this problem, the Simulink application of the MATLAB was used. Particularly, a block diagram was built where the equation for FMEP from the Winterbone model into a system that works with a controller was integrated.

Using a PID type controller, the speed was adjusted in which during the simulation time, the FMEP was kept at the low levels. It is necessary to find the equation of the maximum pressure as a function of speed or temperature. A PID controller was chosen, because such controllers are used universally in industry, requiring accurate and optimized automatic control.

The equations analyzed in the previous paragraphs and now will be introduced in the structured diagram designed in Simulink. The corresponding expressions are given as:

Friction mean effective pressure equation (FMEP):

$$
F M E P=0.061+0.15 \cdot \frac{P \max }{60}+0.294 \cdot \frac{n}{1000}
$$

Equation of maximum pressure $(P \max )$ as a function of speed:

$$
P \max =1 \mathrm{E}-09 \mathrm{n}^{3}-9 \mathrm{E}-06 \mathrm{n}^{2}+0,0268 \mathrm{n}+1,936
$$

Therefore, using the appropriate blocks from the Simulink library, the corresponding diagram is illustrated in Fig. 5.

\section{Results and discussion}

\subsection{Model validation}

The present analysis proposed a computational framework based on Reynolds equation for simulating compression ring tribo-system. Figure 6 shows the flow conditions along the ringliner contact. Fully flooded inlet conditions are assumed. The combustion pressure and the outlet pressure (from crankcase) values are considered as input depending on the direction of piston motion. The input gas pressures are also presented in Eq. (20) where $p_{a}$ is the ambient gas pressure.

$$
\left\{\begin{array}{l}
p\left(x, \frac{b}{2}\right)= \begin{cases}p_{\text {in }}=p_{c} & \text { for upstoke } \\
p_{\text {out }}=p_{c} & \text { for downstroke }\end{cases} \\
p\left(x,-\frac{b}{2}\right)= \begin{cases}p_{\text {out }}=p_{a} & \text { for upstoke } \\
p_{\text {in }}=p_{a} & \text { for downstroke }\end{cases}
\end{array}\right.
$$

In this analysis, the combustion pressure is taken overall behind the piston ring profile into the piston groove. Following this assumption, further investigation is needed regarding gas blow-by and elastic ring performance into the piston groove. This means that these shortcomings may affect the computed predictions. Gas blow-by is more accurate to predict gas pressures on piston ring [37]. This point was not within the scope of the current work.

The results are obtained here at crank angle of 21 degrees when high combustion pressure acts on the top compression ring for engine speed of $1500 \mathrm{rpm}$ and isothermal conditions. In detail, a high-performance top compression ring is modeled. Inlet and outlet gas pressures are illustrated in the graph as the piston ring moved at crank angle of $21^{\circ}$ during downstroke. In this case, the ambient pressure $p_{a}$ is taken as inlet and the combustion pressure $p_{c}=5 \mathrm{MPa}$ is assumed to be the outlet condition. These boundary conditions are argued with the work of Shahmohamadi et al. [16]. The results of 1D Reynolds equation with half Sommerfeld conditions are also represented by the black line in Fig. 7. The CFD analysis (dotted black line) was taken from the Navier-Stokes approach including vapor transport.

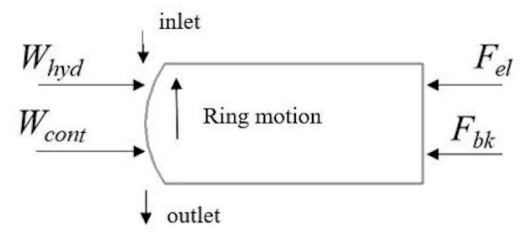

Fig. 6 Flow conditions in piston ring-liner contact

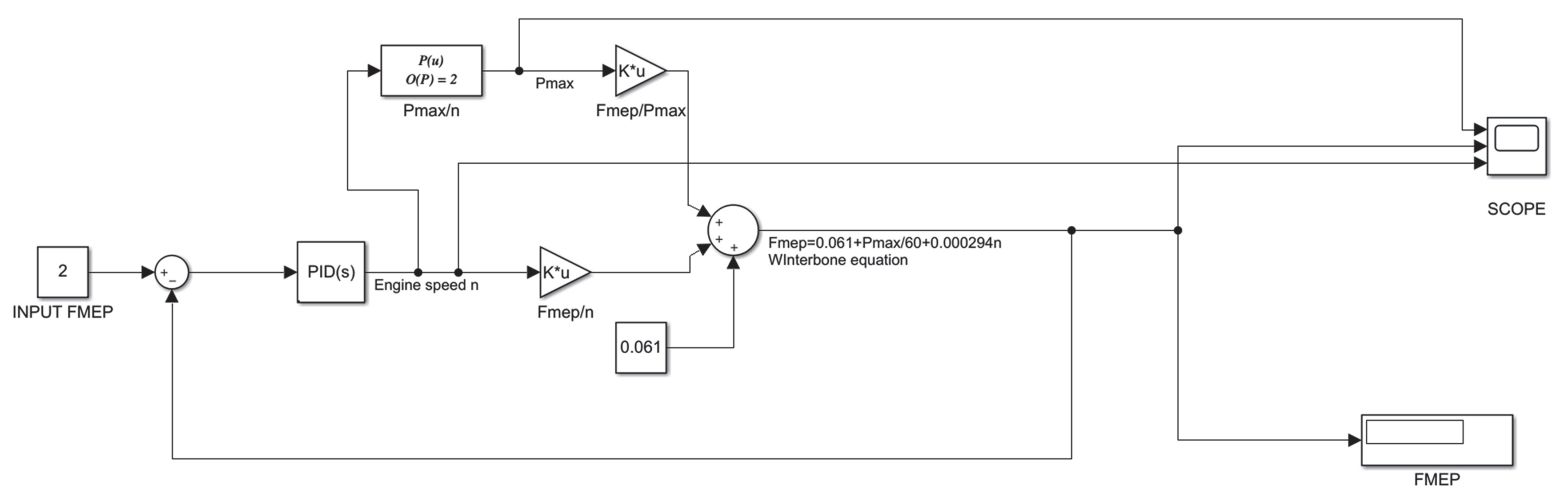

Fig. 5 A schematic view of the final block diagram in simulink 


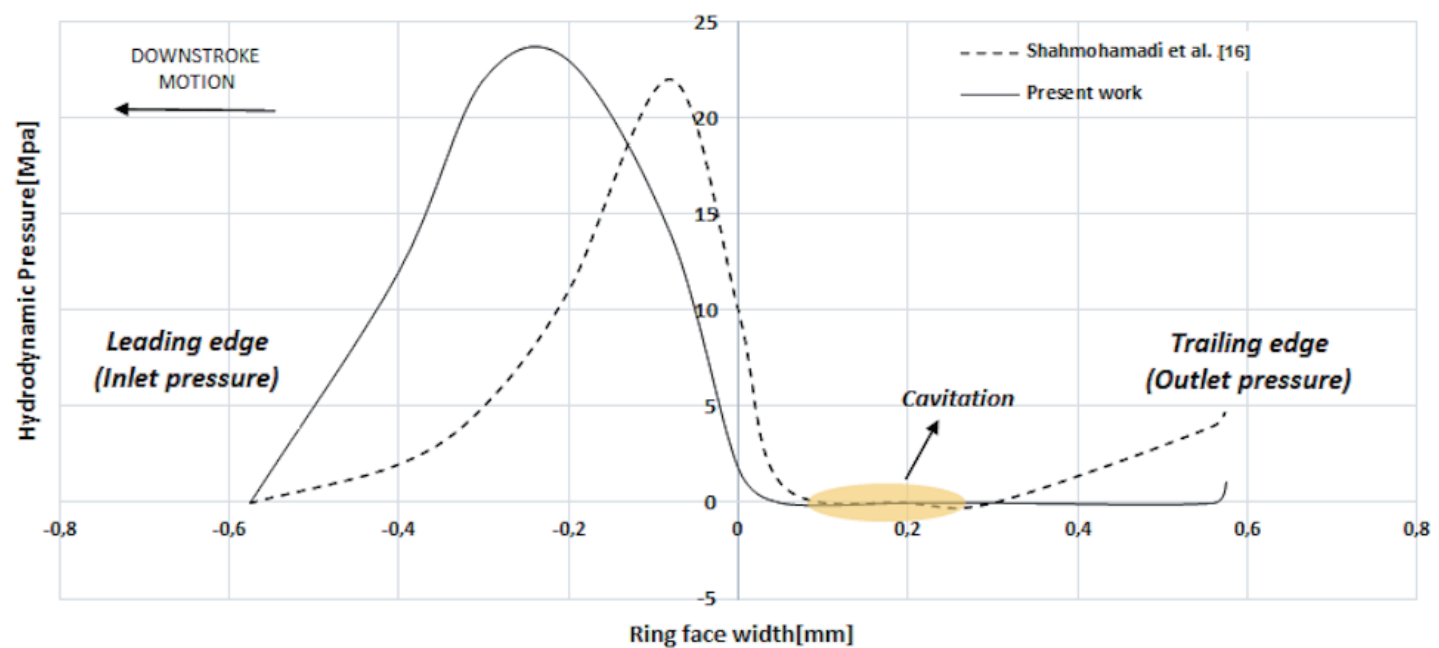

Fig. 7 Validation results at crank angle of $21^{\circ}$ during downstroke. Comparison between predictions with the CFD data of Shahmohamadi et al. [16]

No changes in the lubricant rheology within the film along the ring profile will be taken into account directly in the current work. Thus, the generated hydrodynamic pressures are not uniform with the CFD predictions. However, the deviation of the two models at the point of the maximum pressure is $6 \%$. The analysis showed here that the maximum pressure has good conformance. Additionally, it is obvious that the Reynolds equation is limited at the outlet region of the ring profile, where cavitation and lubricant film rupture is not taken into account. Note there is a notably difference on the film rupture point (gray area) between the algorithms with cavitation and without cavitation (half Sommerfeld model condition). This behavior becomes because the mass conservation of the fluid in the cavitation zone is not attained. In more details, the solution of 2D Navier-Stokes equations has greater solution time. However, the advantage of the Reynolds equation is the faster solution, and easier to handle than the solution of the Navier-Stokes.

Some simulations for this study are also illustrated in Fig. 8 (a-b). Therefore, an advanced simulation model comprising two-phase flow, viscosity variation and heat transfer should be sought in the future step of this analysis. The current study has a major scope to comprise a numerical model with an automatic control system using faster and simpler accurately results, in order to pay attention in the tribotronics design. In Figs. 8(a) and $8(\mathrm{~b})$, the pressure distribution at crank angles of 21 and 90 degrees are presented as a function of the width, corresponds to the number of grid nodes. It is observed that the maximum pressure is higher enough at 21 degrees because of its very close to the power stroke.

\subsection{Test engine specifications}

The piston ring-liner system analyzed here was based on a four-stroke, high performance gasoline engine V12. Table 1 lists the test engine data. The ring dimensions, the material properties and the roughness parameters are also provided according to the work of Shahmohamadi et al. [16].

Figure 8 shows the used engine running conditions, including the sliding velocity in Fig. 9(a) and the pressure cylinder's pressure in Fig. 9 (b). The simulation studies were taken at lubricant temperatures. The type of lubricant was SAE 10W40. Particularly, the idle engine speeds are significant for modern engines during the urban driving (traffic). According to Taylor et al. [38] and Zavos et al. [37], the effect of low engine speeds on power losses have shown prime of importance. They analyzed the effect of lubricant rheology in the boundary/mixed and hydrodynamic lubrication conditions

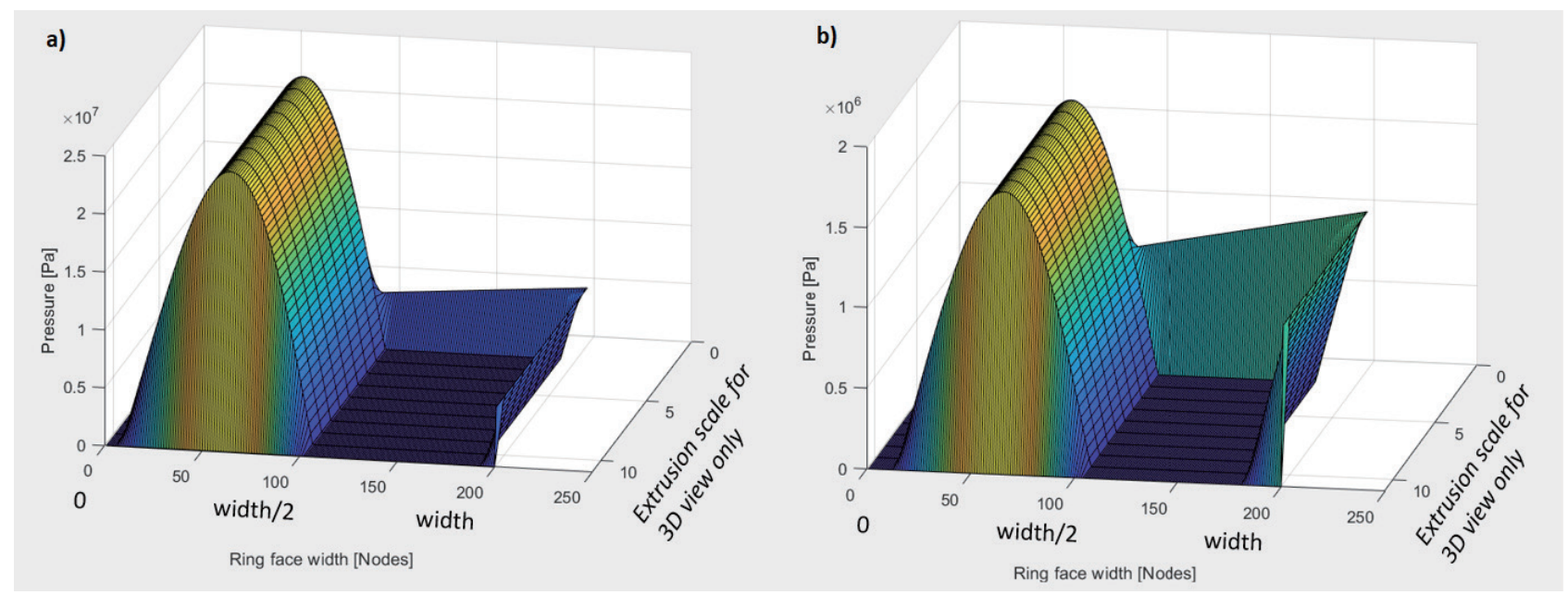

Fig. 8 (a) Pressure distribution at crank angle of $21^{\circ}$ using MATLAB environment, (b) Pressure distribution at crank angle of $90^{\circ}$ using MATLAB environment 
Table 1 Engine and piston ring-liner data

\begin{tabular}{|c|c|c|}
\hline Parameter & Value & Unit \\
\hline Engine type & $\begin{array}{l}\text { Gasoline, four-stroke, high } \\
\text { performance engine V12 }\end{array}$ & - \\
\hline Displacement & 5954.6 & $\mathrm{~cm}^{3}$ \\
\hline Nominal cylinder diameter, $D_{c y l}$ & 90 & $\mathrm{~mm}$ \\
\hline Crank-pin radius, $r$ & 39 & $\mathrm{~mm}$ \\
\hline Rod length, $l_{\text {rod }}$ & 138 & $\mathrm{~mm}$ \\
\hline Idle rotational speed, $N$ & 1500 & rpm \\
\hline Ring radial width, $w$ & 3.5 & $\mathrm{~mm}$ \\
\hline Ring face-width, $b$ & 1.15 & $\mathrm{~mm}$ \\
\hline Ring curvature, $c$ & 10 & $\mu \mathrm{m}$ \\
\hline Piston-ring end gap, $d_{g a p}$ & 10 & $\mathrm{~mm}$ \\
\hline Roughness parameter, $\zeta \kappa \sigma$ & 0.04 & $\longrightarrow$ \\
\hline Ring base material & Steel & 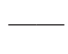 \\
\hline Young modulus of elasticity for ring, $E_{r}$ & 203 & $\mathrm{GPa}$ \\
\hline Ring Poisson's ratio, $v_{r}$ & 0.3 & 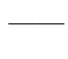 \\
\hline Cylinder liner base material & Grey cast iron & 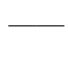 \\
\hline Young modulus of elasticity for liner, $E_{c y l}$ & 92.3 & $\mathrm{GPa}$ \\
\hline Liner Poisson's ratio, $v_{c y l}$ & 0.211 & $\longrightarrow$ \\
\hline
\end{tabular}
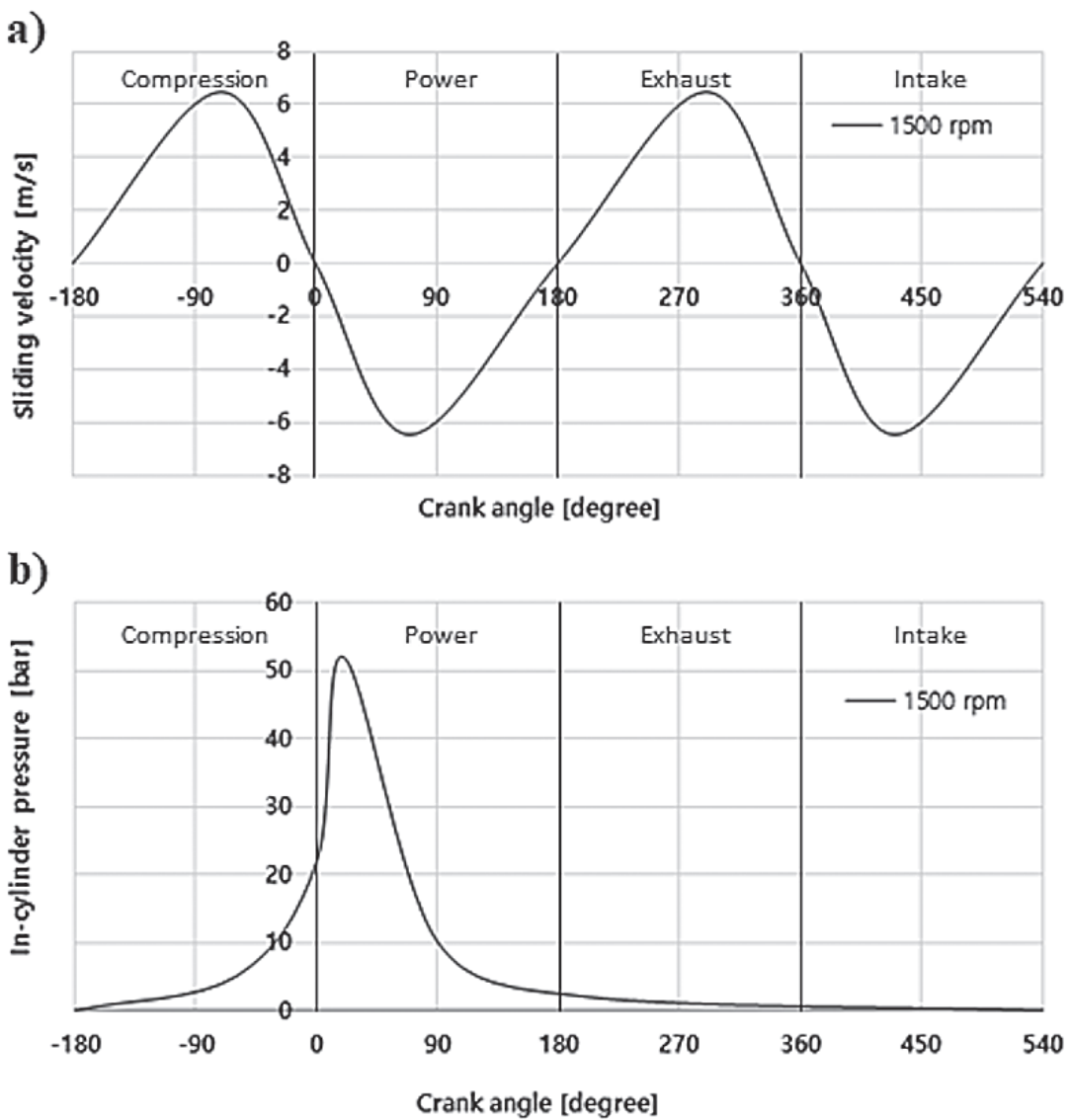

Fig. 9 Engine running conditions: a) the sliding ring velocity and b) the in-cylinder pressure 
for various low speeds. Under these conditions, the issues of lubricant degradation, engine load and speed should be further presented. These conditions remain the motivation for further improvement of the proposed study.

5.3 Maximum pressure as a function of engine speed

To design the model, the change in maximum pressure $\left(P_{\max }\right)$ as a function of speed $(n)$ must be considered and the function connecting the two terms should be obtained.

We run the code in MATLAB for a range of speed values $n[0$ to 5000] and gather the results for maximum pressure (Fig. 10). The maximum gas pressure occurs in the power stroke between the TDC reversal and the mid-stroke position. This can be explained because there is significant in-cylinder pressure load on the piston ring-liner contact, which follows the relationship between the shear stress and pressure $\tau \propto \pm \frac{h}{2} \nabla p$ from the first term in expression of the viscous shear stress of the lubricant film: $\tau=\left| \pm \frac{h}{2} \nabla p-\Delta \vec{V} \frac{\mu}{h}\right|$. Additionally, the regression method was used to obtain the equation that approximates the maximum pressure - speed function.

The maximum pressure equation as a function of speed used in the Simulink model will be:

$$
P \max =1 \mathrm{E}-09 \mathrm{n}^{3}-9 \mathrm{E}-06 \mathrm{n}^{2}+0,0268 \mathrm{n}+1,936
$$

As it is mentioned, the aim of the simulation is to adjust the gains of the PID controller so that the output (FMEP) remains at the levels we want for the entire duration of the simulation. To perform the simulation, the desired value range for FMEP must be set. The range of FMEP in the context of this analysis will be 0.19 MPa and 0.2 MPa. This will adjust the controller so that FMEP is limited to these values.

In order to set the controller, the simulation was run for various PID gains values and collect the results. In such way, it is able to control for which values of the controller's gains the FMEP reaches the desired values.

The aim is to design the simplest controller that will meet the specifications of the problem. To adjust the controller in our system, the values of the gains $\mathrm{Kp}, \mathrm{Ki}$ and $\mathrm{Kd}$ must be regulated to a point that the friction mean effective pressure FMEP is within the desired limits that they have been set, [1.9-2.0] $10^{5}$ $\mathrm{Pa}$. Also, the simplest controller design must be provided. Consequentially, the step-by-step procedure is presented, how the controller's gains can be achieved (Fig. 11).
After testing different types of PID and continuous adjustment of controller gains it was found that an ID controller set with $\mathrm{Ki}=45, \mathrm{Kd}=3$ stabilizes FMEP to $0.19 \mathrm{MPa}$ (Fig. 12).

For the high limit of FMEP $=0.2 \mathrm{MPa}$, we found that an ID controller (Fig. 13) with $\mathrm{Ki}=100, \mathrm{Kd}=3$ gains helps to stabilizes FMEP to the desirable limit. This is shown in Fig. 14.

5.4 FMEP calculation for different temperatures and design of new PID controllers

The purpose of this paragraph analysis is the calculation of controllers' parameters for different values of temperature in relation to the effect of aging on the engine oil. The target is to examine the impact of temperature variation and aging of the lubricant in maximum pressure, Friction Mean Effective Pressure (FMEP) and finally, the impact in the design of PID gains. The data for the correlation between the aging of the oil and temperature were used from recent publication of Nikolakopoulos et al. [33].

The analysis will be similar to the previous paragraphs 5.1 to 5.3. Thus, the already designed code will be used to calculate the maximum gas pressure as a function of engine speed. Three different values of temperatures have been used. The engine oil that used in the models is synthetic oil SAE 10W40. Initially used in its fresh state, and then after of $100 \mathrm{hr}$ aged.

In Fig. 2, it can be seen that the viscosity changes in relation with temperature and aging. The equation of maximum pressure regarding the two states of the lubricant for $40^{\circ} \mathrm{C}, 55^{\circ} \mathrm{C}$ and $70^{\circ} \mathrm{C}$ has been calculated.

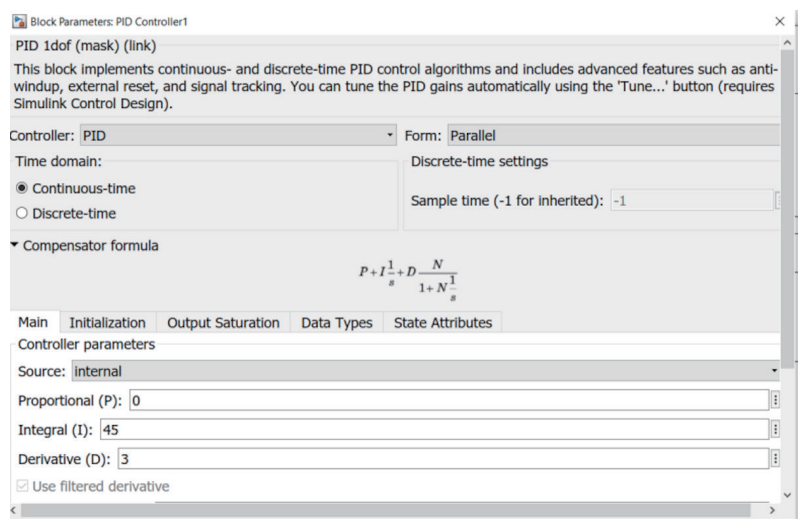

Fig. 11 Adjustment of controller gains for minimum FMEP = $0.19 \mathrm{MPa}$

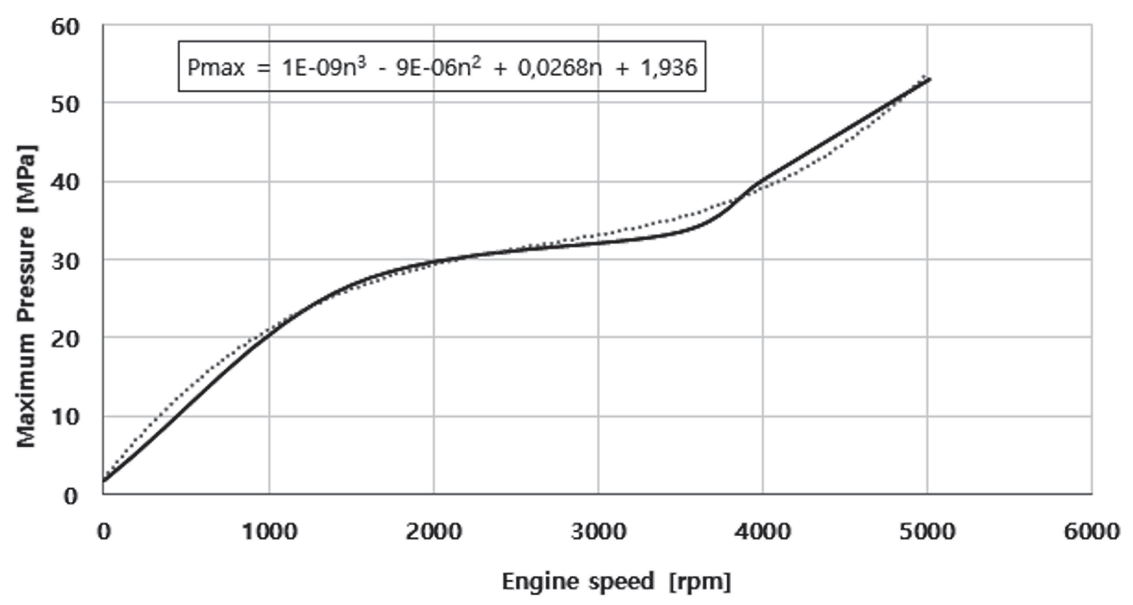

Fig. 10 Maximum pressure as a function of engine speed using polynomial regression method 


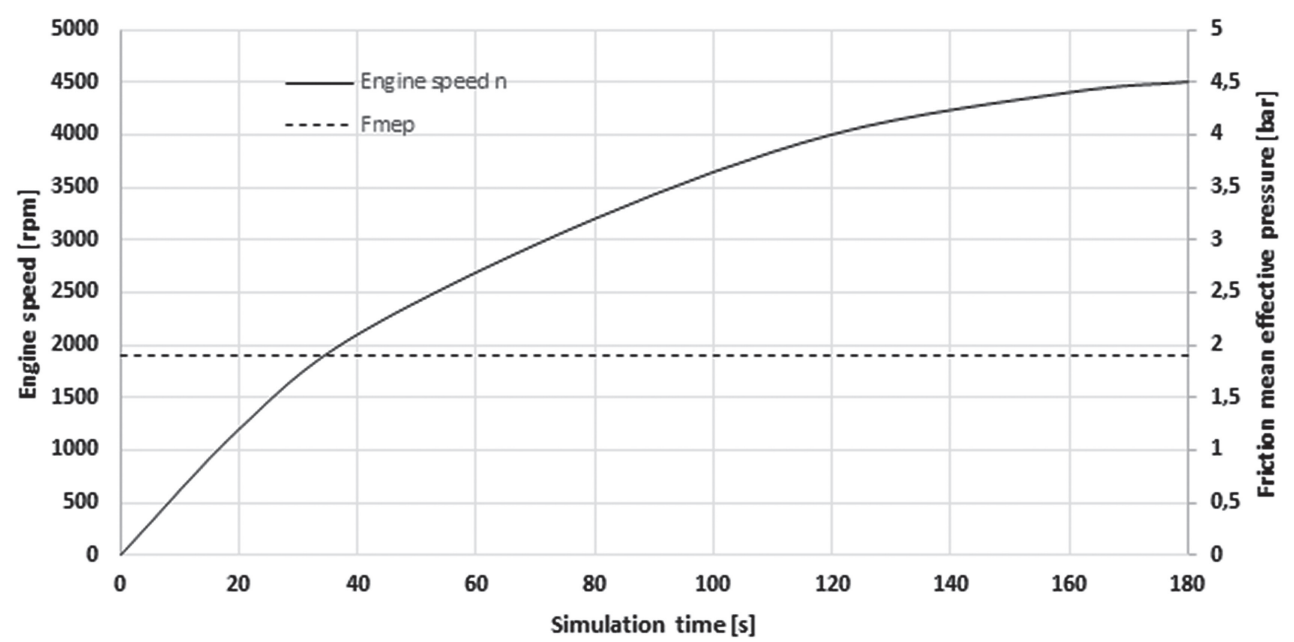

Fig. 12 Response of engine speed and FMEP for minimum value of $0.19 \mathrm{MPa}$

The viscosity values were obtained from Fig. 2 and used as inputs to the MATLAB code. The maximum pressure has been calculated for an engine speed range [0 $-4000 \mathrm{rpm}]$. After

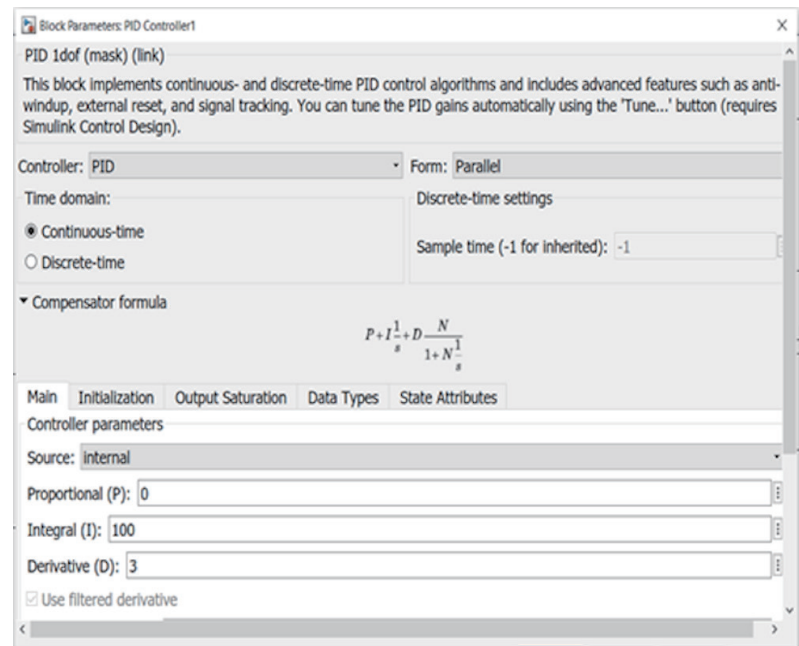

Fig. 13 Adjustment of controller gains for maximum FMEP = $0.2 \mathrm{MPa}$ that, the maximum pressure as a function of engine speed for different values of viscosity (of fresh and aged oil) is shown in Fig. 15, and the polynomial regression method was used in to obtain the necessary approximations.

Using the regression method, the equations results are also given in the Table 2. Further, the equations of Table 2 were introduced through the Simulink model. Afterwards, a new PID controller is found, of each lubricant state, that can be used to stabilize the friction mean effective pressure (FMEP) to the desired limits. With regard to these particular cases, the limit of FMEP = $2 \mathrm{MPa}$ was set equal to input FMEP and in continue, the simulation was run for $180 \mathrm{sec}$.

After several testing of the controller parameters, the minimum values that help to complete the task of limiting the FMEP to 2 MPa were calculated. In the Table 3, the results of the PID gains are presented. Further the comparison between the PID gains for the different temperatures and states of the engine oil are depicted in Fig. 16.

From the above, it can be concluded that the increment of the temperature results an increase in the gains of the controller as it has changed the maximum pressure equation. As can be seen, the synthetic oil SAE 10W40 brings different results while the temperatures rise. It is observed, that when the temperature

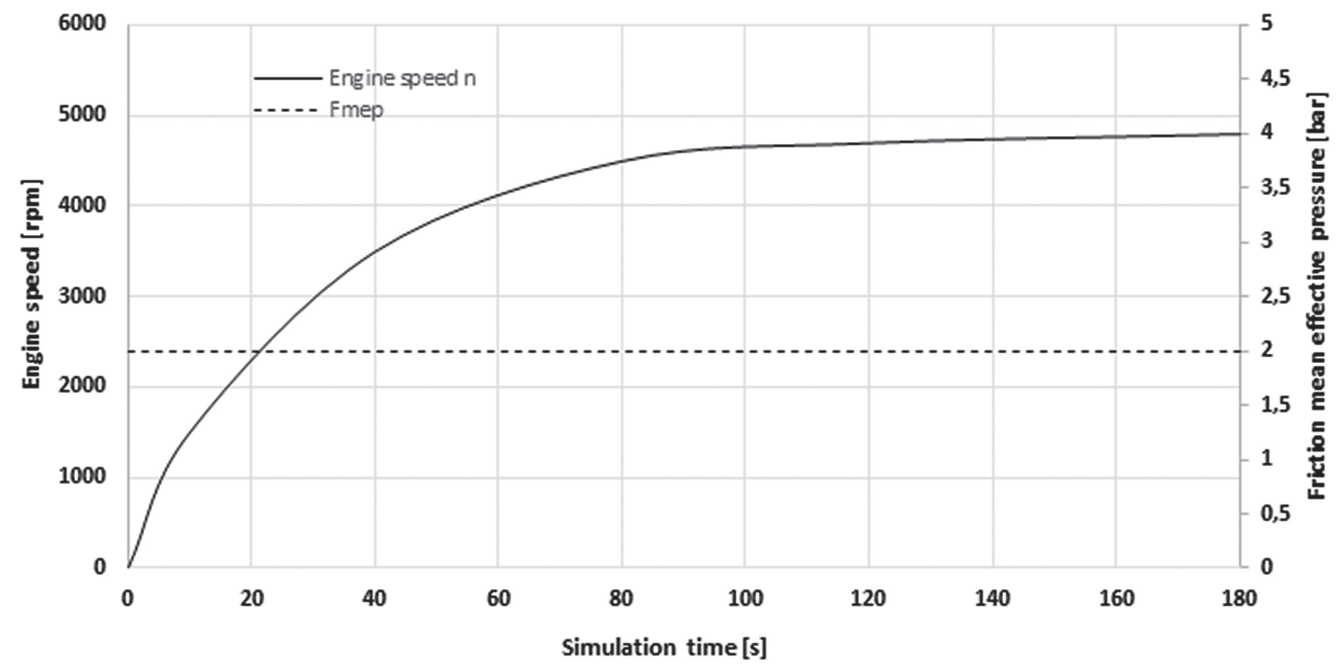

Fig. 14 Response of engine speed and FMEP for maximum value of $0.2 \mathrm{MPa}$ 
is set at $40^{\circ} \mathrm{C}$, there is no difference in the maximum pressure equation of the FMEP model. On the contrary, when the temperature rises (from $55^{\circ} \mathrm{C}$ to $70^{\circ} \mathrm{C}$ ), the difference between the fresh and aged oil gets larger, resulting in much more different values of the controller's parameters. This is a reasonable result, as it is known the correlation between the viscosity and the state of the lubricant.

Cavitation is an important parameter in the piston ring

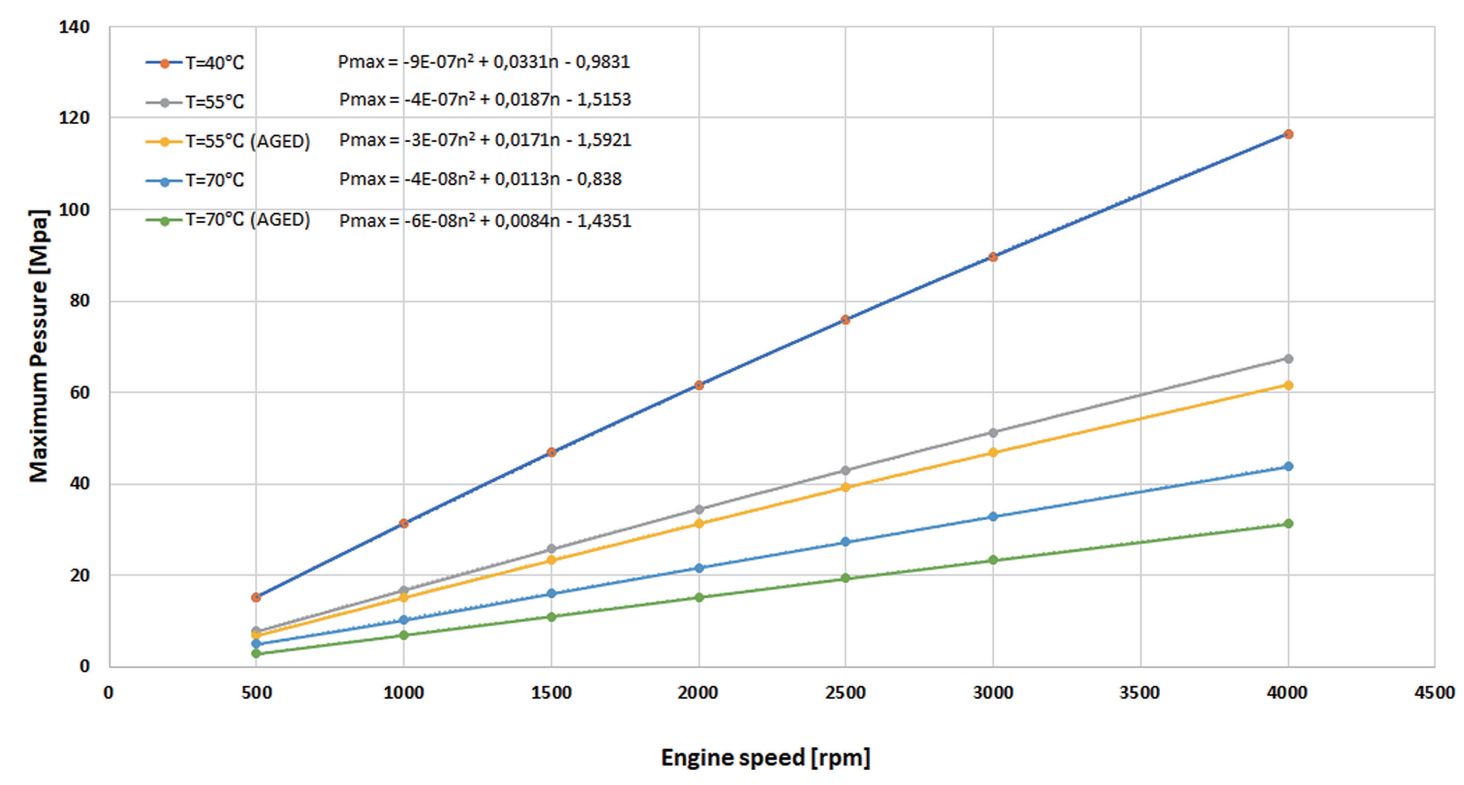

Fig. 15 Maximum pressure values with the rotational speed

Table 2 Maximum pressure equations for different states of the lubricant

\begin{tabular}{|c|c|c|}
\hline \multicolumn{3}{|c|}{ Maximum pressure as a function of engine speed } \\
\hline Temperature $\left({ }^{\circ} \mathrm{C}\right)$ & Fresh SAE 10W40 & Aged SAE 10W40 \\
\hline 40 & $P_{\max }=-9 \mathrm{E}-07 \mathrm{n}^{2}+0,0331 \mathrm{n}-0,9831$ & $P_{\max }=-9 \mathrm{E}-07 \mathrm{n}^{2}+0,0331 \mathrm{n}-0,9831$ \\
\hline 55 & $P_{\max }=-4 \mathrm{E}-07 \mathrm{n}^{2}+0,0187 \mathrm{n}-1,5153$ & $P_{\max }=-3 \mathrm{E}-07 \mathrm{n}^{2}+0,0171 \mathrm{n}-1,5921$ \\
\hline 70 & $P_{\max }=-4 \mathrm{E}-08 \mathrm{n}^{2}+0,0113 n-0,838$ & $P_{\max }=-6 \mathrm{E}-08 \mathrm{n}^{2}+0,0084 n-1,4351$ \\
\hline
\end{tabular}

Table 3 PID gains for different states of the lubricant

\begin{tabular}{|c|c|c|c|c|c|c|}
\hline & \multicolumn{3}{|c|}{ SAE 10W40 } & \multicolumn{3}{c|}{ SAE 10W40 100hr AGED } \\
\cline { 2 - 7 } & $\mathbf{P}$ & I & D & P & I & D \\
\hline$T=40^{\circ} \mathrm{C}$ & 0 & 50 & 2 & 0 & 50 & 2 \\
\hline$T=55^{\circ} \mathrm{C}$ & 0 & 70 & 2 & 0 & 75 & 2 \\
\hline$T=70^{\circ} \mathrm{C}$ & 0 & 85 & 3 & 0 & 95 & 3 \\
\hline
\end{tabular}

PID GAINS

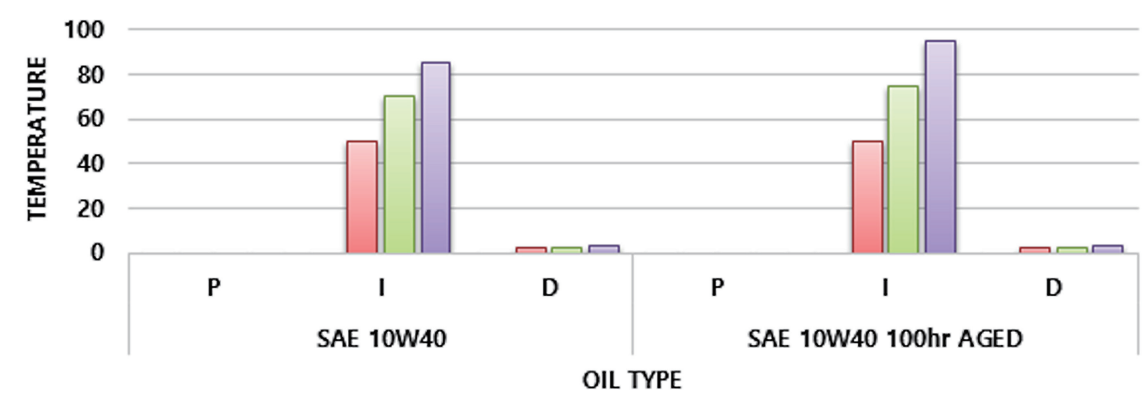

$\square \mathrm{T}=40^{\circ} \mathrm{C} \quad \square \mathrm{T}=55^{\circ} \mathrm{C} \quad \square \mathrm{T}=70^{\circ} \mathrm{C}$

Fig. 16 Comparison of PID gains for different lubricant temperatures 
tribology. Either using Navier Stokes equations or Reynolds equation for the solution, the suitable cavitation model, and under certain operational conditions could affect the results [25, 39]. Figure 17 shows the variation of maximum pressure for different engine speeds using a cavitation model at lubricant temperature of $55^{\circ} \mathrm{C}$. The Rayleigh Plesset cavitation model was used here to obtain results with cavitation. Further information on cavitation model can be also found in Zavos and Nikolakopoulos work [39]. Table 4 presents the relevant results concerning the maximum pressure as a function of engine speed. As the engine speed is increased, results of FMEP are changed more owing to cavitation effects on ring load capacity $[16,39]$. The increment of engine speed has predominant impact on lubricant streamlines within the ring-liner conjunction, leading to different pressure profiles. This finding supports the work reported by Shahmohamadi et al. [16] who outlined the importance of cavitation flow upon pressure profiles and frictional losses. This trend can influence controller gains modifications as it is illustrated in Fig. 18. It can be seen that the cavitation affects the controller's integral gain by $20 \%$ in respect to the case without cavitation considerations.

\section{Conclusions}

A combined analysis was presented here to proof the tribotronics design in an Internal Combustion Engine. The Reynolds equation was solved to compute the hydrodynamic pressures in the area of the compression piston rings, and to find the FMEP function. Afterwards, the FMEP is used to design a PID controller in order the engine, through the piston ring, to operate in the predetermined FMEP limits. The major conclusions are the followings:
1. The tribotronics can be applied in the design level of the combustion engine.

2. The increment of the lubricant temperature, affecting in the viscosity, results an increase in the gains of the controller.

3. It is observed that, when the temperature increases from lower to higher values (from $40^{\circ} \mathrm{C}$ to $55^{\circ} \mathrm{C}$ and $70^{\circ} \mathrm{C}$ respectively), the difference between the fresh and aged oil regarding the tribotronics gets bigger, resulting thus in much more different values of the controller parameters, providing thus the necessity of the tribotronics design.

4. The CFD predictions are clearly influenced from the cavitation phenomenon. The increment of engine speed affect highly the lubrication conditions into the ring-liner contact. This would lead to different pressure profiles. This trend also showed the importance of cavitation flow upon load and speed. Therefore, this behavior can ensure controller gains modifications by $20 \%$ in respect to the case without cavitation considerations.

Further actions regarding the impact of thermoelastic phenomena and starvation should be addressed for future research, in order to design more precisely the tribotronics system, through the controller's parameters.

\section{Nomenclature}

$\begin{array}{ll}A & \text { nominal contact area } \\ A_{\text {cont }} & \text { asperity contact area } \\ b & \text { ring face-width } \\ c & \text { ring face-width curvature height } \\ D_{c y l} & \text { cylinder diameter } \\ d_{\text {gap }} & \text { piston-ring end gap }\end{array}$

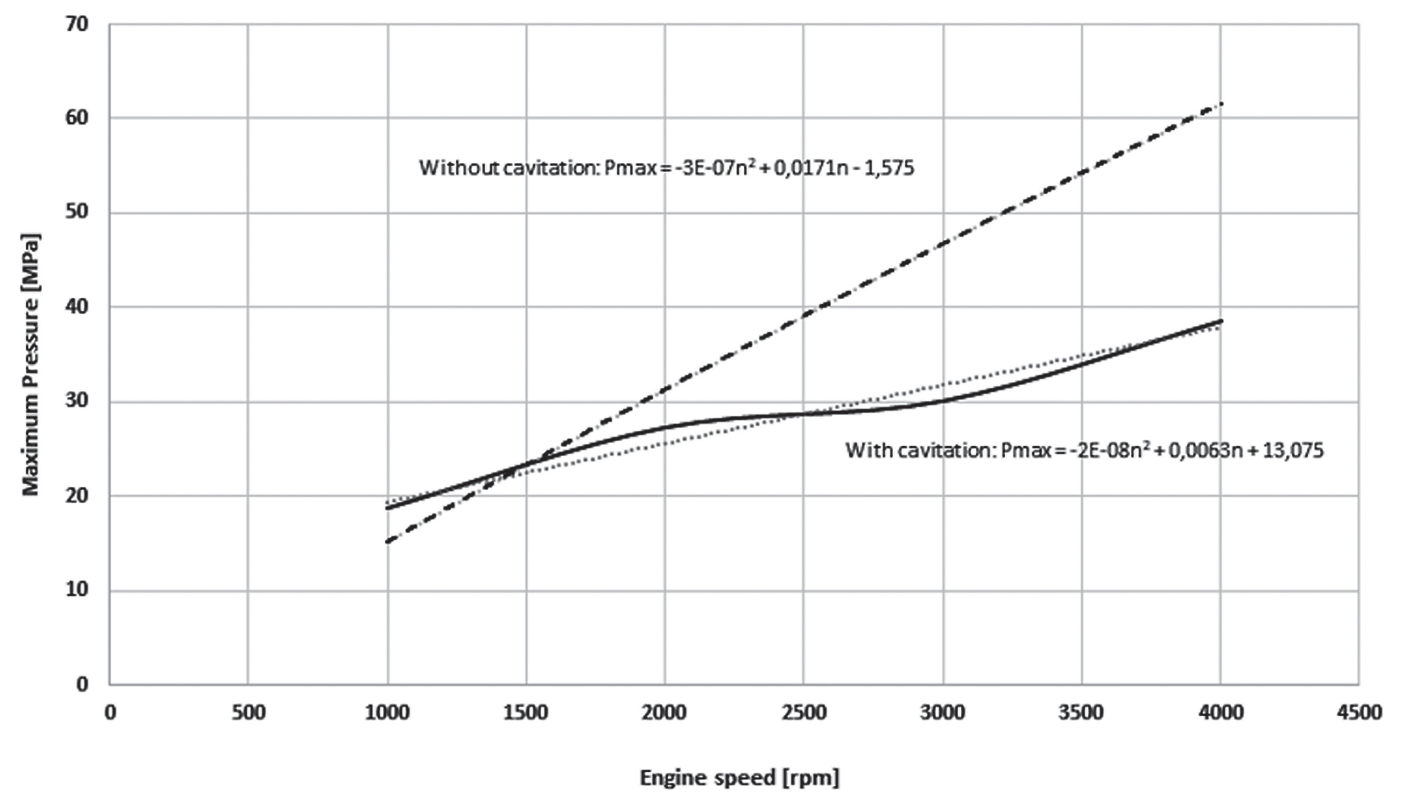

Fig. 17 Maximum pressure values with the rotational speed using a cavitation model [39] for lubricant temperature of $55^{\circ} \mathrm{C}$

Table 4 Maximum pressure equations with and without cavitation model for lubricant temperature of $55^{\circ} \mathrm{C}$

\begin{tabular}{|c|c|c|}
\hline & \multicolumn{3}{|c|}{ Maximum pressure as a function of engine speed } \\
\hline Temperature $\left({ }^{\circ} \mathrm{C}\right)$ & Without cavitation model & With cavitation model \\
\hline 55 & $P_{\max }=-3 \mathrm{E}-07 \mathrm{n}^{2}+0,0187 \mathrm{n}-1,5153$ & $\mathrm{P}_{\max }=-2 \mathrm{E}-08 \mathrm{n}^{2}+0,0063 \mathrm{n}+13,075$ \\
\hline
\end{tabular}


100

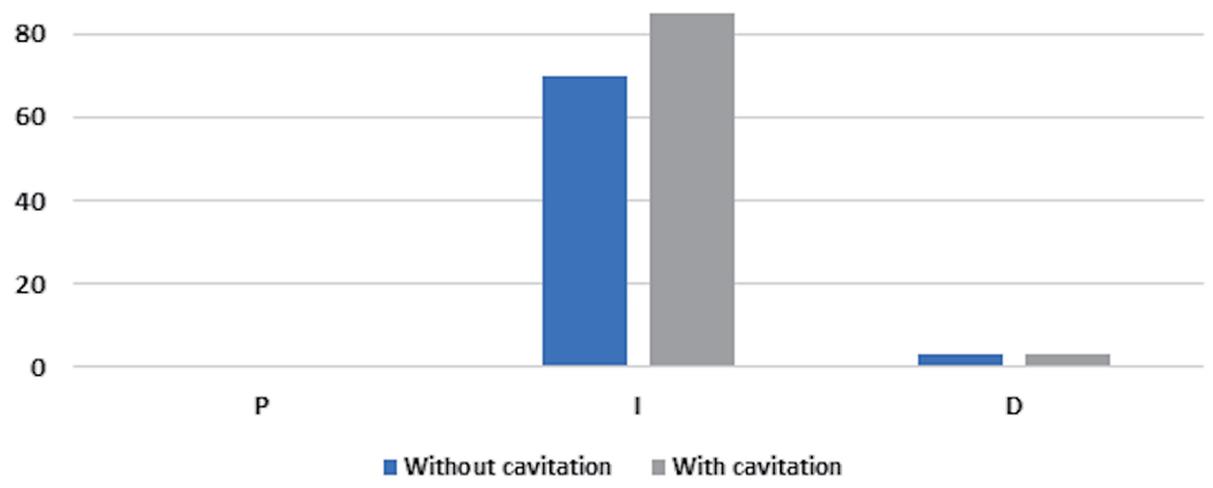

Fig. 18 Comparison of PID gains with cavitation model [39] and without for lubricant temperature of $55^{\circ} \mathrm{C}$

$E^{\prime} \quad$ equivalent (reduced) modulus of elasticity

$E_{r} \quad$ Young's modulus of elasticity of the ring

$E_{c y l} \quad$ Young's modulus of elasticity of the liner

$F \quad$ applied ring load

$F_{b k} \quad$ back gas force

$F_{e l} \quad$ ring tension force

$F_{5 / 2}, F_{2}$ statistical functions

$h \quad$ lubricant film thickness

$h_{\text {min }} \quad$ minimum film thickness

$h_{s} \quad$ ring axial profile

$I_{\text {ring }} \quad$ second moment of ring

$l_{\text {rod }} \quad$ rod length $(m)$

$p \quad$ static pressure

$p_{\text {hyd }} \quad$ hydrodynamic pressure

$p_{e l} \quad$ ring elastic pressure due to fitment

$p_{b k} \quad$ ring back gas pressure acting behind the inner ring rim

$p_{c} \quad$ combustion pressure

$p_{i n} \quad$ inlet (leading) pressure at the ring conjunction

$p_{\text {out }} \quad$ outlet (trailing) pressure at the ring conjunction

$p_{a} \quad$ ambient pressure

$r \quad$ crank-pin radius

$r_{o} \quad$ nominal bore radius

$t$ time

$w \quad$ ring radial width

$W_{\text {cont }} \quad$ load share of asperities

$W_{\text {hyd }} \quad$ load carried by the lubricant film

$x$ direction of entraining motion

$y \quad$ circumferential degree of freedom

\section{Greek symbols}

surface density of asperity peaks

$\lambda \quad$ Stribeck oil film parameter

$\lambda_{C R} \quad$ control ratio

$\mu \quad$ lubricant dynamic viscosity

$v_{r}, v_{c y l}$ ring and cylinder Poisson's ratio

$N \quad$ engine speed in rpm

$\sigma_{r} \quad$ surface roughness value of the ring

$\sigma_{c y l} \quad$ surface roughness value of the liner $(m)$

$\sigma \quad$ root mean square roughness value of examined tribo pair

$\tau \quad$ viscous shear stress

$V_{r} \quad$ ring sliding velocity $(\mathrm{m} / \mathrm{s})$

$\varphi \quad$ crank angle $\left({ }^{\circ}\right)$

$\chi \quad$ step for minimum film thickness loop

$X \quad$ load balance parameter

$\omega \quad$ rotational crankshaft speed

\author{
Abbreviations \\ AFM Atomic Force Microscope \\ BMEP Brake Mean Effective Pressure \\ CFD Computational Fluid Dynamics \\ FMEP Friction Mean Effective Pressure \\ ICE Internal Combustion Engine \\ IMEP Indicated Mean Effective Pressure \\ JFO Jakobsson-Floberg-Olsson \\ MEP Mean Effective Pressure \\ PID Proportional Integration Derivative
}

\section{References}

[1] Holmberg, K. and Erdemir, A., "Influence of Tribology on Global Energy Consumption, Costs and Emissions," Friction, 5, 3, 2017, 263-284.

[2] Ragupathi, P., Barik, D., Vignesh, G. and Aravind, S., "Electricity Generation from Exhaust Waste Heat of Internal Combustion Engine Using $\mathrm{Al}_{2} \mathrm{O}_{3}$ Thermoelectric Generators," Journal of Applied Science and Engineering, 23, 1, 2020, 55-60.

[3] Tung, S. C. and McMillan, M. L., "Automotive Tribology Overview of Current Advances and Challenges for the Future," Tribology International, 37, 7, 2004, 517-536.

[4] Ferreira, R., Martins, J., Carvalho, Ó., Sobral, L., Carvalho, S. and Silva, F., "Tribological Solutions for Engine Piston Ring Surfaces: An Overview on the Materials and Manufacturing," Materials and Manufacturing Processes, 35, 5, 2020, 498-520.

[5] Richardson, D. E., "Review of Power Cylinder Friction for Diesel Engines," J. Eng. Gas Turbines Power, 122, 4, 2000, 506-519.

[6] Dowson, D., Economou, P. N., Ruddy, B. L., Strachan, P. J. and Baker, A. J. S., "Piston Ring Lubrication. Part II: Theoretical Analysis of a Single Ring and a Complete Ring Pack," Energy Conservation Through Fluid Film Lubrication Technology: Frontiers in Research and Design, 1979, 23-52.

[7] Furuhama, S., "A Dynamic Theory of Piston-Ring Lubrication: 2nd Report, Experiment," Bulletin of JSME, 3, 10, 1960, 291-297.

[8] Jeng, Y. R., "Theoretical Analysis of Piston-Ring Lubrication Part IFully Flooded Lubrication. Tribology Transactions," 35, 4, 1992, 696706.

[9] Priest, M., Dowson, D. and Taylor, C. M., "Theoretical Modelling of Cavitation in Piston Ring Lubrication," Proceedings of the Institution of Mechanical Engineers, Part C: Journal of Mechanical Engineering Science, 214, 3, 2000, 435-447.

[10] Ma, M. T., Smith, E. H. and Sherrington, I., "Analysis of Lubrication and Friction for a Complete Piston-Ring Pack with an Improved 
Oil Availability Model: Part 2: Circumferentially Variable Film," Proceedings of the Institution of Mechanical Engineers, Part J: Journal of Engineering Tribology, 211, 1, 1997, 17-27.

[11] Nikolakopoulos, P. G., "Simulation of Deposits Effect on Cylinder Liner and Influence on New and Worn Compression Ring of a Turbocharged DI Engine," Simulation Modelling Practice and Theory, 106, 2021, 102195.

[12] Rahmani, R., Rahnejat, H., Fitzsimons, B. and Dowson, D., “The Effect of Cylinder Liner Operating Temperature on Frictional Loss and Engine Emissions in Piston Ring Conjunction," Applied Energy, 191, 2017, 568-581.

[13] Bewsher, S. R., Turnbull, R., Mohammadpour, M., Rahmani, R., Rahnejat, H., Offner, G. and Knaus, O., "Effect of Cylinder DeActivation on the Tribological Performance of Compression Ring Conjunction," Proceedings of the Institution of Mechanical Engineers, Part J: Journal of Engineering Tribology, 231, 8, 2017, 9971006.

[14] Arcoumanis, C., Duszynski, M., Flora, H. and Ostovar, P., “Development of a Piston-Ring Lubrication Test-Rig and Investigation of Boundary Conditions for Modelling Lubricant Film Properties," SAE Transactions, 1995, 1433-1451.

[15] Sawicki, J. T. and Yu, B., "Analytical Solution of Piston Ring Lubrication Using Mass Conserving Cavitation Algorithm," Tribology Transactions, 43, 3, 2000, 419-426.

[16] Shahmohamadi, H., Rahmani, R., Rahnejat, H., Garner, C. P. and King, P. D., “Thermo-Mixed Hydrodynamics of Piston Compression Ring Conjunction," Tribology Letters, 51, 3, 2013, 323-340.

[17] Tian, T., "Dynamic Behaviours of Piston Rings and Their Practical Impact. Part 1: Ring Flutter and Ring Collapse and Their Effects on Gas Flow and Oil Transport," Proceedings of the Institution of Mechanical Engineers, Part J: Journal of Engineering Tribology, 216, 4, 2002, 209-228.

[18] Baker, C., Theodossiades, S., Rahmani, R., Rahnejat, H. and Fitzsimons, B., "On the Transient Three-Dimensional Tribodynamics of Internal Combustion Engine Top Compression Ring," Journal of Engineering for Gas Turbines and Power, 139, 6, 2017.

[19] Sherrington, I., "Tribotronics -Part of a Pathway to Sustainable Engineering?," Proc. ECOTRIB 2017, Ljubljana, 2017.

[20] Sherrington, I. and Smith, E. H., "Algorithmic Control of Lubrication in Tribotronic Systems," Proc. LUBMAT 2018, Spain, 2018.

[21] Bahrudin, M. S., Abdullah, S. F. and Khan, M. R. B., "Friction Measurement System Using Load Cell for Tribotronic System on Pin-On-Disc (POD) Tribometer," Proc. 4th International Conference on Energy and Environment, Malaysia, 2013, 1-4.

[22] Glavatskih, S. and Höglund, E., "Tribotronics-Towards Active Tribology," Tribology International, 41, 9-10, 2008, 934-939.

[23] Zhang, C. and Wang, Z. L., "Tribotronics - A New Field by Coupling Triboelectricity and Semiconductor," Nano Today, 11, 4, 2016, 521-536.

[24] Haddad, S. D. and Tjan, K. T., "An Analytical Study of Offset Piston and Crankshaft Designs and the Effect of Oil Film on Piston Slap
Excitation in a Diesel Engine," Mechanism and Machine Theory, 30, 2, 1995, 271-284.

[25] Morris, N., Rahmani, R., Rahnejat, H., King, P. D. and Fitzsimons, B., "Tribology of Piston Compression Ring Conjunction under Transient Thermal Mixed Regime of Lubrication," Tribology International, 59, 2013, 248-258.

[26] Reynolds, O., "On the Theory of Lubrication and Its Application to Mr. Beauchamp Tower's Experiments, Including an Experimental Determination of the Viscosity of Olive Oil," Phil. Trans. Roy. Soc., 1, $1885,157$.

[27] Yun, J. E., Chung, Y., Chun S. M. and Lee, K. Y., “An Application of Simplified Average Reynolds Equation for Mixed Lubrication Analysis of Piston Ring Assembly in an Internal Combustion Engine," SAE Technical Paper, 952562, 1995.

[28] Jakobsson, B. and Floberg, L., "The Finite Journal Bearing, Considering Vaporization," Chalmers Tekniska Högskolas Handlingar, Chalmers University of Technology, 1957.

[29] Olsson, K., "Cavitation in Dynamically Loaded Bearings," Chalmers University of Technology, Technical Report, 308, 1965.

[30] Mishra, P. C., Rahnejat, H. and King, P. D., "Tribology of the RingBore Conjunction Subject to a Mixed Regime of Lubrication," Proceedings of the Institution of Mechanical Engineers, Part C: Journal of Mechanical Engineering Science, 223, 4, 2009, 987-998.

[31] Zavos, A. and Nikolakopoulos, P., "Thermo-Mixed Lubrication Analysis of Coated Compression Rings with Worn Cylinder Profiles," Industrial Lubrication and Tribology, 69, 1, 2017, 15-29.

[32] Gohar, R. and Rahnejat, H., "Fundamentals of Tribology," Imperial College Press: London, UK, 2008.

[33] Nikolakopoulos, P. G., Mavroudis, S. and Zavos, A., "Lubrication Performance of Engine Commercial Oils with Different Performance Levels: The Effect of Engine Synthetic Oil Aging on Piston Ring Tribology under Real Engine Conditions," Lubricants, 6, 4, 2018, 90.

[34] Hamatake, T., Wakuri, Y., Soejima, M. and Kitahara, T., "Effects of Lubricant Viscosity on the Mixed Lubrication of a Piston Ring Pack in an Internal Combustion Engine," Lubrication Science, 15, 2, 2003, 101-117.

[35] Stone, R., "Introduction to Internal Combustion Engines," Search PubMed, 1999.

[36] Greenwood, J. A. and Tripp, J. H., “The Contact of Two Nominally Flat Rough Surfaces," Proc. Inst. Mech. Eng., 185, 1970, 625-633.

[37] Zavos, A. and Nikolakopoulos, P. G., "Investigation of the Top Compression Ring Power Loss and Energy Consumption for Different Engine Conditions," Tribology -Materials, Surfaces \& Interfaces, 2021, https://doi.org/10.1080/17515831.2021.1907682.

[38] Taylor, R. I., Morgan, N., Mainwaring, R. and Davenport, T., “How Much Mixed/Boundary Friction is There in an Engine-and Where is It?," Proceedings of the Institution of Mechanical Engineers, Part J: Journal of Engineering Tribology, 234, 10, 2020, 1563-1579.

[39] Zavos, A. and Nikolakopoulos, P. G., "Cavitation Effects on Textured Compression Rings in Mixed Lubrication," Lubrication Science, 28, 8, 2016, 475-504.

This paper is licensed under the Creative Commons Attribution-NonCommercial-NoDerivatives 4.0 International (CC BY-NC-ND 4.0) International License. This allows users to copy and distribute the paper, only upon conditions that (i) users do not copy or distribute such paper for commercial purposes, (ii) users do not change, modify or edit such paper in any way, (iii) users give appropriate credit (with a link to the formal publication through the relevant DOI (Digital Object Identifier)) and provide a link to this license, and (iv) users acknowledge and agree that users and their use of such paper are not connected with, or sponsored, endorsed, or granted official status by the Licensor (i.e. Japanese Society of Tribologists). To view this license, go to https://creativecommons.org/licenses/by-nc-nd/4.0/. Be noted that the third-party materials in this article are not included in the Creative Commons license, if indicated on the material's credit line. The users must obtain the permission of the copyright holder and use the third-party materials in accordance with the rule specified by the copyright holder. 